\title{
Severe acral erythrodysesthesia and docetaxel
}

\section{Justin Bagorane, Mohammed El Fadli, Gustave Negamiyimana, Ephraim Lonté Kintossou, Ganiou Adjade, Kalil Cisse, Nada Benhima, Rhizlane Belbaraka}

\author{
Department of Medical Oncology, CHU Mohammed VI, University Cadi Ayyad, Marrakech, Morocco
}

Corresponding author: Justin Bagorane, MD, E-mail: bagoraneju@gmail.com

Acral erythrodysesthesia can have a serious impact on the patient's quality of life and on their ability to continue or complete treatment [1].

We report a case of a 42-year-old female followed for breast cancer: cT4d N2 M0; RH + / HER2 3+. She received neoadjuvant chemotherapy based on anthracycline sequentially by docetaxel associated with trastuzumab and pertuzumab in HER2 dual-blocking strategy. The evolution was marked, after the first cycle of docetaxel dual-blocking, by the occurrence of severe skin toxicity in the form of acral erythrodysesthesia in the soles of the feet and causing the patient an inability to walk. (Figs. la and lb). She was immediately referred to a plastic surgery department and was made aware of the physical measures to be observed for good remission of the skin toxicity. The administration of docetaxel treatment was immediately discontinued, after which the patient completed the treatment with paclitaxel.

Preventive measures and early recognition of acral erythrodysesthesia remain the essential strategies to ensure timely treatment and avoidance of dose reductions or treatment discontinuation [2].

\section{Consent}

The examination of the patient was conducted according to the principles of the Declaration of Helsinki.

The authors certify that they have obtained all appropriate patient consent forms, in which the patients gave their consent for images and other clinical information to be included in the journal. The

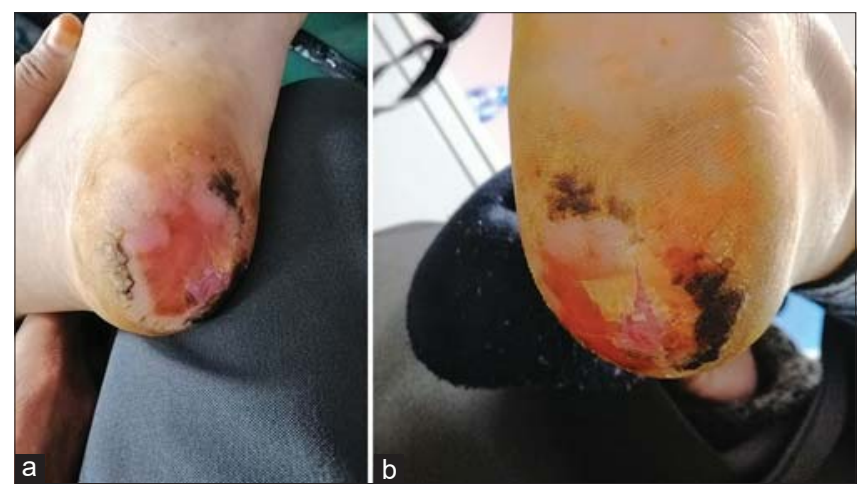

Figure 1: (a-b) Grade III acral erythrodysesthesia in the soles of the feet, one week after the first dose of docetaxel-trastuzumabpertuzumab chemotherapy.

patients understand that their names and initials will not be published and due effort will be made to conceal their identity, but that anonymity cannot be guaranteed.

\section{REFERENCES}

1. Kwakman JJM, Elshot YS, Punt CJA, Koopman M. Management of cytotoxic chemotherapy-induced hand-foot syndrome. Oncol Rev. 2020;14:442.

2. Kwakman JJM, Simkens LHJ, van Rooijen JM, van de Wouw AJ, Ten Tije AJ, Creemers GJM, et al. Randomised phase III trial of S-1 versus capecitabine in the first-line treatment of metastatic colorectal cancer: SALTO study by the Dutch Colorectal Cancer Group. Ann Oncol. 2017;28:1288-93.

Copyright by Justin Bagorane, et al. This is an open-access article distributed under the terms of the Creative Commons Attribution License, which permits unrestricted use, distribution, and reproduction in any medium, provided the original author and source are credited. Source of Support: Nil, Conflict of Interest: None declared.

\footnotetext{
How to cite this article: Bagorane J, El Fadli M, Negamiyimana G, Kintossou EL, Adjade G, Cisse K, Benhima N, Belbaraka R. Severe acral erythrodysesthesia and docetaxel. Our Dermatol Online. 2021;12(2):197.

Submission: 29.08.2020; Acceptance: 31.10.2020

DOI: $10.7241 /$ ourd.20212.25
} 